\title{
A method for selection of parameters of ship propulsion system fitted with compromise screw propeller
}

\author{
Jan P. Michalski, Assoc. Prof. \\ Gdańsk University of Technology \\ Polish Naval University
}

\begin{abstract}

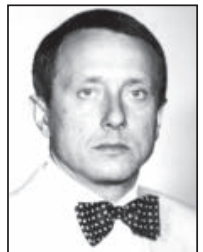

This paper concerns an algorithmic method for preliminary selection of parameters of ship propulsion system fitted with fixed screw propeller in the case when the ship's operation is associated with significant changes of waterway depth and width, hull resistance of the ship and its service speed. Mathematical model arguments of the considered design problem are main ship design parameters identified in the preliminary design stage. Structure of the formulated model complies with formal requirements for continuous-discrete mathematical optimization problems. The presented examples of application of the method concern an inland waterways ship fitted with compromise screw propeller optimized in the sense of minimization of fuel consumption for passing a given route distance within a given time. The elaborated method may be especially useful in designing such ships as : coasters, inland waterways ships, tugs, pushers, trawlers, mine sweepers, icebreakers etc.
\end{abstract}

Keywords : design of inland waterways ships, ship propellers, ship propulsion

\section{INTRODUCTION AND PROBLEM DESCRIPTION}

A method for selection of rational, or optimum in a given sense, technical solutions of a ship should take into account, already in the preliminary design stage, both obligatory and crucial design conditions and constraints. This paper concerns a method for determining, in the preliminary design stage, optimum values of the parameters of ship propulsion system fitted with fixed screw propeller in the case where hull resistance and service speed of the ship significantly varies during operation, that often takes place in the case of inland navigation.

Design process of inland navigation ships should takes into account the demand of adjusting the ship to future real service tasks including ship operation at significantly variable propulsion performance characteristics of the ship, whose variability results from :

* changeable hydrographic conditions in water area of ship operation - shallow waters, narrow canals of variable width, winding river bends

* significant changes of ship draught and displacement during voyage

* frequent events of ship running aground and re-floating - unavoidable in shallow waters

* hull resistance changes at various hull configurations - in the case of multi-hull arrangement.
Polish inland waterways are of small depth and often have the form of unregulated narrow river beds. In such case are fully justified the reasons for the application to inland navigation ships the propulsion systems with fixed screw propellers as they, in comparison with those with controllable pitch propellers, are characterized by :

low manufacturing, assembling and possible repair costs of the propellers

$\checkmark$ higher reliability and resistance against failure during stranding

$\checkmark$ higher power conversion efficiency.

For operators of inland navigation ships the high reliability of propulsion system and easiness of its repair possible to be done even in almost any conditions along trip route are of crucial importance.

\section{CLASSICAL PROBLEM STATEMENT}

In the standard design method of preliminary selection of ship propulsion system parameters the following phases can be distinguished:

$+1^{\text {st }}$ phase of the approximate determining of nominal hull resistance characteristics in function of the speed $\mathbf{v}$, ship and waterway parameters $\overline{\mathbf{p}}$

$$
\mathrm{R}=\mathrm{R}(v, \overline{\mathrm{p}})
$$


as well as the hull-propeller interaction coefficients, i.e. the wake fraction $\mathbf{w}=\mathrm{w}(v, \overline{\mathrm{p}})$ and thrust deduction $\mathbf{t}=\mathrm{t}(\mathrm{v}, \overline{\mathrm{p}})$

$+2^{\text {nd }}$ phase of the determining of demanded power characteristics as well as geometrical parameters of screw propeller including its diameter, pitch, number of blades, and expanded blade area coefficient in function of ship speed and number of revolutions of propeller and engine; this is a basis for rational choice of an engine (-s) from producer catalogues.

In the subject-matter literature the above described design procedure is called,,thrust approach” or „naval architect's approach"; it leads to selection of propeller parameters and a specific engine of determined rated power and rotational speed. The ship's designer - in cooperation with the ship's owner and engine producer - determines permissible values of the engine's operation parameters, in particular its continuous rating, rotational speed and supercharging parameters. The selection of continuous rating parameters of the chosen engine in the form of its torque $\mathbf{Q}$ and rotational speed $\mathbf{n}$ makes it possible to select values of parameters of power transmission devices and screw propeller itself.

The above presented classical design problem may have an unambiguous solution in the case of taking the simplifying assumption consisting in an arbitrary determination of hull resistance characteristics. To this end are assumed the nominal (design) hull resistance characteristics relevant to predicted conditions, i.e. the most probable service conditions of designed ship. Hence an unambiguous value of hull resistance corresponds to the ship speed given in the ship's design assumptions, that forms the basis for the selection of parameters of propulsion system of maximum efficiency which is usually limited by necessity of satisfying a given set of design constraints.

If real ship service conditions appear different from those assumed in design procedure then the propulsion system will operate at a lower efficiency, increased specific fuel consumption, not fully utilized engine output, or with the engine overloaded by torque or rotational speed. The method of solving the classical design problems, described e.g. in [2, $3,4]$, is used here as a comparative background for further considerations.

\section{NON-STANDARD PROBLEM STATEMENT}

In the case of ship propulsion system fitted with fixed screw propeller a non-standard problem of ship design theory is the designing of ship propulsion system at hull resistance characteristics significantly changing during ship service as well as at significantly changing hull -propeller interaction characteristics, $\mathbf{w}$ and $\mathbf{t}$. The subject-matter literature does not provide a fully satisfactory algorithmic method useful in solving the so defined design problems.

The presented considerations are thought as an attempt to eliminate the gap by elaborating a method for selecting the propulsion system with fixed propeller, useful in solving design problems of ships intended for operation in the conditions when :

$\star$ water area is shallow, of changeable depth and/or width $\star$ immersed part of ship hull undergoes intensive fouling

$\star$ ship service is associated with up- and down-stream sailing

$\star$ ship displacement significantly changes during voyage

$\star$ ship service consists in towing or pushing other objects.

Especially important is the case when the ship has to operate both in deep and shallow or restricted waters as then hull resistance characteristics much differ in each of the cases. The water area limitations influence both flow velocity distribution around the hull and ship-generated wave system (pressure distribution). Beginning from the limit speed up to critical one, hull resistance suddenly increases $[6,9]$. Moreover the change in flow velocity distribution around the hull due to waterway bank effects makes the wake fraction and thrust deduction coefficients changing, thus they become variable, which seriously influences propeller performance.

The above described non-standard problem of determining the designed ship propulsion system parameters is of an utilitarian importance both technical and economical, however so far no fully satisfactory solution has been found for it in spite of the great interest paid to the problem $[5,6,7]$.

The method in question exemplifies such a method for selecting the ship propulsion system parameters, which takes into account both changeable operational conditions of screw propeller and changeable hull resistance, and also arbitrary design constraints to be satisfied, and moreover which makes it possible to determine such values of the system's parameters which optimize the propulsion system in a certain sense.

\section{MATHEMATICAL MODEL OF THE DESIGN PROBLEM}

\section{Assumptions of the method for selecting the propulsion parameters}

The screw propeller designing in accordance with the classical approach $[2,3,4]$ consists in such selection of its geometrical characteristics as to obtain maximum value of propulsion efficiency and full utilization of continuous rating of driving engine at a given rotational speed in ship service conditions complying with its design assumptions. Moreover, the designed screw propeller should fulfill operational reliability criteria both for the propeller itself and elements cooperating with it.

In design practice, fulfillment of reliability requirements is equivalent to selection of a suitable material for the propeller as well as of geometrical parameters of the propeller in such a way as to ensure its sufficient strength and resistance against cavitation erosion.

Continuous service output power of the engine is usually taken as its characteristic power and its relation to engine's rated power depends on engine's dynamic performance and a way of determining the rated power, which depends on a type of engine and standards applied by producers of particular engines.

The continuous service output power is assumed a little smaller than, or equal to maximum continuous rating which the engine is capable of developing at a given rotational speed and not exceeding a permissible thermal load. However the so determined output power is usually not acceptable to ship owners for the reason of values of time between engine overhauls demanded by them; hence on ship owner's request the service output power value is lowered by a few percent, and the lower output has to be developed at rated rotational speed or that somewhat lower.

\section{Decision variables and parameters of the model}

In accordance with formulation principles of the mathematical optimization problems the mathematical model of the considered design problem, built under appropriate simplifying assumptions, contains :

- a target function to be minimized (or maximized)

* constraints in the form of equalities and inequalities, resulting from technical sense of the design problem 
* a vector of optimized decision variables together with permissible ranges of their determination

* a set of approximate analytical characteristics of the phenomena taken into account in the model.

The propulsion system with fixed screw propeller is considered as that commonly applied to ships operating in shallow waters $[1,6,8]$.

The considered service route of the ship in question consists $\boldsymbol{m}$ waterway sections whose lengths are described by the vector $\overline{\mathbf{r}}=\left(\mathrm{r}_{1}, \mathrm{r}_{2}, \ldots \mathrm{r}_{\mathrm{m}}\right)$. The waterway sections differ to each other by the parameters of water area and of the ship $\overline{\mathbf{p}}_{\mathrm{i}}=\left(\mathrm{p}_{\mathrm{i}, 1}, \mathrm{p}_{\mathrm{i}, 2}, \ldots\right)$, which significantly affect propulsion system's performance.

The hull resistance $\mathbf{R}_{\mathbf{i}}\left(v_{\mathrm{i}}, \overline{\mathrm{p}}_{\mathrm{i}}\right)$ in $i$-th water area of length $\mathbf{r}_{\mathbf{i}}$ depends on the parameters $\overline{\mathbf{p}}_{i}$ and ship speed $\mathbf{v}_{\mathbf{i}}$ developed over this section of the route. Moreover the hull resistance characteristics can be corrected by means of the coefficients $\xi_{i}$ which represent arbitrarily assumed service margins.

Ship's speeds over particular route sections are described by the vector $\bar{v}=\left(v_{1}, v_{2}, \ldots v_{\mathrm{m}}\right)$ determined during optimization process, and the propulsion system efficiency $\eta(\bar{v}, \bar{p}, \bar{s})$ over particular route sections depends on the propeller parameters $\overline{\mathbf{s}}=\left(\mathrm{s}_{1}, \mathrm{~s}_{2}, \ldots\right)$, waterway parameters, water inflow velocity as well as parameters of ship's hull form assumed here fixed, i.e. not subjected to any correction and optimization.

In the model in question the following was assumed :

$$
\overline{\mathrm{p}}_{\mathrm{i}}=\left(\mathrm{p}_{\mathrm{i}, 1}, \mathrm{p}_{\mathrm{i}, 2}, \mathrm{p}_{\mathrm{i}, 3}\right) \text { and } \overline{\mathrm{s}}=\left(\mathrm{s}_{1}, \mathrm{~s}_{2}, \mathrm{~s}_{3}, \mathrm{~s}_{4}, \mathrm{~s}_{5}\right)
$$

where :

$\mathrm{p}_{\mathrm{i}, 1}=\mathrm{h}_{\mathrm{i}} / \mathrm{T}$ - ratio of the depth of $i$-th route section and ship's draught

$\mathrm{p}_{\mathrm{i}, 2}=\mathrm{b}_{\mathrm{i}} / \mathrm{B}$ - ratio of the width of $i$-th route section and ship's breadth

$\mathrm{p}_{\mathrm{i}, 3}=\mathrm{vs}_{\mathrm{i}}$ - current speed over $i$-th route section

$\mathrm{s}_{1}=\mathrm{z}$ - number of propeller blades, from the set $\{3,4,5\}$

$\mathrm{s}_{2}=\mathrm{S}_{0} / \mathrm{S}$ - propeller expanded blade area ratio, from the set $\{0.55,0.65,0.70,0.75\}$

$\mathrm{s}_{3}=\mathrm{D} \quad$ - propeller diameter not greater than that maximum permissible $\mathrm{D} \leq \mathrm{D}_{\max }$

$\mathrm{s}_{4}=\mathrm{H} / \mathrm{D}$ - propeller pitch ratio, one of the decision variables of the model, to be determined during optimization process

$\mathrm{s}_{5}=\mathrm{n} \quad$ - number of propeller revolutions, one of the decision variables of the model, to be determined during optimization process.

\section{Target function to be minimized}

The demanded propulsion power $\mathbf{P}(v, \overline{\mathrm{p}}, \overline{\mathrm{s}}$,$) , necessary$ to obtain the ship speed $\mathbf{v}_{\mathbf{i}}$ over the route section $\mathbf{r}_{\mathbf{i}}$, can be expressed as follows :

$$
\begin{gathered}
P_{i}=\frac{\xi_{i} R\left(v_{i}, \bar{p}_{i}\right) v_{i}}{\eta\left(v_{i}, \bar{p}_{i}, \bar{s}\right)}= \\
=\frac{\xi_{i} R\left(v_{i}, \bar{p}_{i}\right) v_{i}}{\eta_{p}\left(v_{i}, \bar{p}_{i}, \bar{s}\right) \xi_{k}\left(v_{i}, \bar{p}_{i}, \bar{s}\right) \xi_{r}\left(v_{i}, \bar{p}_{i}, \bar{s}\right) \eta_{t}(\bar{s})}
\end{gathered}
$$

The fuel cost $\mathbf{K}_{\mathbf{i}}$ consumed to cover the distance of the section $\mathbf{r}_{\mathbf{i}}$ with the speed $\mathbf{v}_{\mathbf{i}}$ is equal to :

$$
\begin{gathered}
\mathrm{K}_{\mathrm{i}}\left(v_{\mathrm{i}}, \overline{\mathrm{p}}_{\mathrm{i}}, \overline{\mathrm{s}}\right)=\operatorname{kjgj}\left(\mathrm{s}_{5}\right) \mathrm{P}\left(\mathrm{v}_{\mathrm{i}}, \overline{\mathrm{p}}_{\mathrm{i}}, \overline{\mathrm{s}}\right) \tau\left(\mathrm{v}_{\mathrm{i}}\right)= \\
=\frac{\operatorname{kj} \mathrm{gj}\left(\mathrm{s}_{5}\right) \xi_{\mathrm{i}} \mathrm{R}\left(\mathrm{v}_{\mathrm{i}}, \overline{\mathrm{p}}_{\mathrm{i}}\right) \mathrm{r}_{\mathrm{i}}\left(\overline{\mathrm{p}}_{\mathrm{i}}\right)\left[1-\mathrm{w}\left(\mathrm{v}_{\mathrm{i}}, \overline{\mathrm{p}}_{\mathrm{i}}, \overline{\mathrm{s}}\right)\right]}{\eta_{\mathrm{p}}\left(\mathrm{v}_{\mathrm{i}}, \overline{\mathrm{p}}_{\mathrm{i}}, \overline{\mathrm{s}}\right)\left[1-\mathrm{t}\left(\mathrm{v}_{\mathrm{i}}, \overline{\mathrm{p}}_{\mathrm{i}}, \overline{\mathrm{s}}\right)\right] \xi_{\mathrm{r}}\left(v_{\mathrm{i}}, \overline{\mathrm{p}}_{\mathrm{i}}, \overline{\mathrm{s}}\right) \eta_{\mathrm{t}}(\overline{\mathrm{s}})}
\end{gathered}
$$

where :

$\mathrm{kj}$ - unit fuel cost $[€ / \mathrm{t}]$

gj - specific fuel consumption $[\mathrm{g} / \mathrm{kWh}]$

$\tau_{\mathrm{i}}$ - time period to cover the distance of $i$-th route section [h]

$\eta_{\mathrm{p}}$ - open -water propeller efficiency [-]

$\eta_{t}$ - power transmission efficiency (from engine to propeller) [-]

$\xi_{\mathrm{k}}-$ hull "efficiency" characteristics [-]

$\xi_{\mathrm{r}}$ - rotational efficiency [-].

In the presented example of the method the total fuel cost $\mathbf{K}_{\mathbf{c}}$ necessary the ship to cover voyage distance within the assumed time period $\tau_{\mathbf{z}}$, was taken as the criterion subjected to optimization :

$$
\mathrm{K}_{\mathrm{c}}\left(\tau_{\mathrm{z}}\right)=\sum_{\mathrm{i}=1}^{\mathrm{m}} \mathrm{K}_{\mathrm{i}}\left(\mathrm{v}_{\mathrm{i}}, \overline{\mathrm{p}}_{\mathrm{i}}, \overline{\mathrm{s}}, \mathrm{r}_{\mathrm{i}}\right)
$$

The set of values of propulsion system parameters, for which the set of model constraints is satisfied (set of permissible solutions) and the target function simultaneously reaches its minimum value, is considered the optimum solution of the model.

\section{Design constraints of the model}

The presented model was elaborated under the following assumptions :

The voyage route of the total length $\mathbf{r}$ is consisted of $\mathbf{m}$ sections of given waterway characteristics :

$$
r=\sum_{i=1}^{m} r_{i}
$$

The voyage duration time $\boldsymbol{\tau}$ is consisted of the ship sailing time as well as the in-advance-estimated time $\boldsymbol{\tau}_{\mathbf{0}}$-intended for stays in ports, locking operations etc :

$$
\tau=\sum_{\mathrm{i}=1}^{\mathrm{m}} \tau_{\mathrm{i}}+\tau_{0}=\sum_{\mathrm{i}=1}^{\mathrm{m}} \frac{\mathrm{r}_{\mathrm{i}}}{\mathrm{v}_{\mathrm{i}}}+\tau_{0}
$$

The voyage duration time, $\boldsymbol{\tau}_{\mathbf{z}}$, determined by the design assumptions is connected with the speeds $\mathbf{v}_{\mathbf{i}}$ for covering distance of particular route sections, by the following relation :

$$
\sum_{i=1}^{m} \frac{r_{i}}{v_{i}}+\tau_{0} \leq \tau_{z}
$$

The permissible limits for ship's maximum speed over $i$-th route section were assumed as follows :

$$
0<v_{i} \leq v_{i}^{\max } \quad i=1,2, \ldots m
$$

$\Rightarrow$ Optimum propeller diameter is not to exceed that maximum permissible :

$$
\mathrm{D}(\overline{\mathrm{x}}) \leq \mathrm{D}_{\max }
$$

$\Rightarrow$ The range of permissible values of the propeller pitch $\mathbf{H}$ is as follows :

$$
0.6 \leq \frac{\mathrm{H}}{\mathrm{D}} \leq 1.4
$$

Minimum value of the expanded blade area ratio $S_{0} / S$ of the propeller has to satisfy the Keller's cavitation criterion [10] :

$$
\left(\frac{\mathrm{S}_{0}}{\mathrm{~S}}\right)_{\min } \geq \frac{(1.3+0.3 \mathrm{z}) \mathrm{T}_{\mathrm{r}}}{\left(\mathrm{p}_{0}-\mathrm{p}_{\mathrm{d}}\right) \mathrm{D}^{2}}+\mathrm{k}
$$

where :

$\mathrm{z}$ - number of propeller blades

$\mathrm{p}_{0}-\quad$ water pressure at propeller axis

$p_{d}-\quad$ saturated water vapour pressure

$\mathrm{T}_{\mathrm{r}}-$ propeller thrust

$\mathrm{k}=0.1$

D - propeller diameter. 
$\Rightarrow$ Number of propeller rotations is not to exceed that maximum permissible :

$$
\mathrm{n} \leq \mathrm{n}_{\max }
$$

Solution of the problem is searched for within the set of propellers having their hydrodynamic characteristics approximated by continuous analytical relationships. In the computer implementation of the model the characteristics of Wageningen propellers of $\boldsymbol{K} \boldsymbol{a}$ series intended for operation within 19A nozzles, are included [11] :

$$
\begin{gathered}
\mathrm{K}_{\mathrm{T}}\left(\mathrm{J}, \frac{\mathrm{H}}{\mathrm{D}}, \frac{\mathrm{S}_{0}}{\mathrm{~S}}, \mathrm{z}\right) \in \\
\in\left\{\mathrm{K}_{\mathrm{T}}(\mathrm{Ka} 3-65), \mathrm{K}_{\mathrm{T}}(\mathrm{Ka} 4-55),\right. \\
\left.\mathrm{K}_{\mathrm{T}}(\mathrm{Ka} 4-70), \mathrm{K}_{\mathrm{T}}(\mathrm{Ka} 5-75)\right\} \\
\mathrm{K}_{\mathrm{Q}}\left(\mathrm{J}, \frac{\mathrm{H}}{\mathrm{D}}, \frac{\mathrm{S}_{0}}{\mathrm{~S}}, \mathrm{z}\right) \in \\
\in\left\{\mathrm{K}_{\mathrm{Q}}(\mathrm{Ka} 3-65), \mathrm{K}_{\mathrm{Q}}(\mathrm{Ka} 4-55),\right. \\
\left.\mathrm{K}_{\mathrm{Q}}(\mathrm{Ka} 4-70), \mathrm{K}_{\mathrm{Q}}(\mathrm{Ka} 5-75)\right\}
\end{gathered}
$$

\section{APPROXIMATED CHARACTERISTICS OF THE MODEL}

The presented method requires to determine in advance analytical relationships which approximate selected hydrodynamic characteristics of propulsion system, and are expressed in function of the variable design arguments $\overline{\mathbf{x}}$; in particular, it is necessary to have at one's disposal analytical representations of :

$>$ the hydrodynamic characteristics $\mathrm{K}_{\mathrm{T}}(\overline{\mathrm{x}}), \mathrm{K}_{\mathrm{Q}}(\overline{\mathrm{x}}), \eta_{\mathrm{p}}(\overline{\mathrm{x}})$ of propellers

$>$ the hull resistance characteristics $\mathrm{R}(\overline{\mathrm{x}})$ for particular route sections

$>$ the hull-propeller interaction characteristics $\mathrm{w}(\overline{\mathrm{x}})$ and $\mathrm{t}(\overline{\mathrm{x}})$ for particular route sections

$>$ the driving engine performance characteristics $\mathrm{P}(\overline{\mathrm{x}})$.

\section{Analytical hydrodynamic characteristics of propellers}

Making use of the data included in [11] one elaborated computer procedures for determining the analytical characteristics $\mathrm{K}_{\mathrm{T}}(\overline{\mathrm{x}}), \mathrm{K}_{\mathrm{Q}}(\overline{\mathrm{x}}), \eta_{\mathrm{p}}(\overline{\mathrm{x}})$ whose example graphical representation concerning Ka3 - 65 propeller ducted in 19A nozzle is shown in Fig.1.

Hydrodynamic characteristics of ducted propellers Ka 3-65 in nozzle 19A

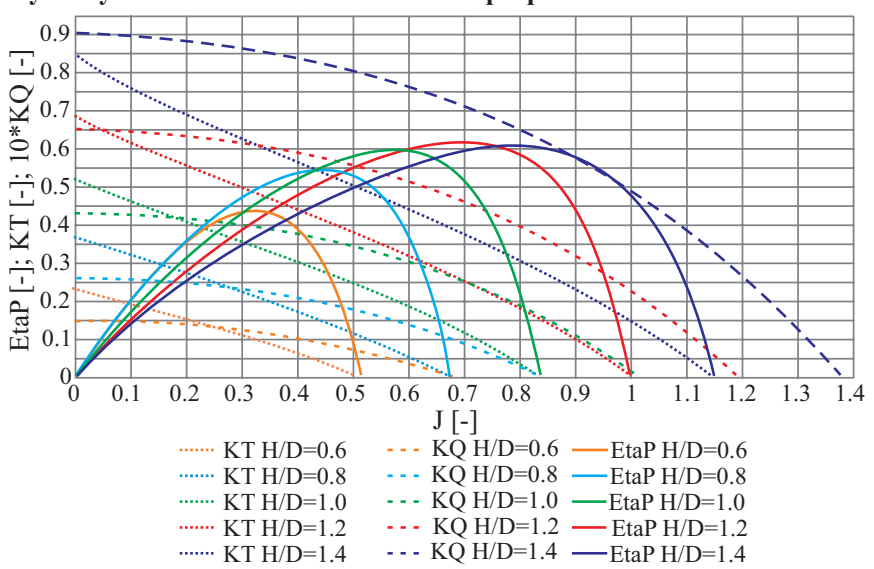

Fig. 1. Example graphical representation of analytically approximated characteristics of propellers

\section{Analytical hull resistance characteristics}

On the basis of the results of hull resistance model tests [12] their analytical approximation was performed and as a result the continuous hull resistance characteristics versus ship speed and water area parameters [13] were achieved. The graphical representation of the approximated hull resistance curves is shown in Fig. 2.

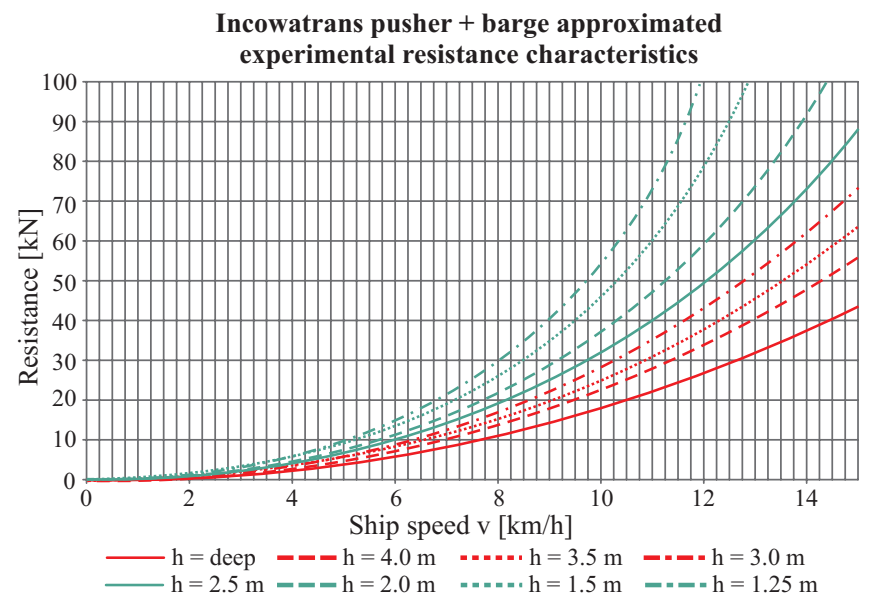

Fig. 2. Graphical representation of the approximated hydrodynamic characteristics of hul resistance.

\section{Analytical characteristics of hull - propeller interaction}

By making use of the elaborated method for determining the hull-propeller interaction characteristics in restricted waters [14] the characteristics of the coefficients $\mathbf{w}(\overline{\mathbf{x}})$ and $\mathbf{t}(\overline{\mathbf{x}})$ for the hull in question and particular route sections, were determined. The so obtained characteristics are presented in Fig.3 and 4, respectively.

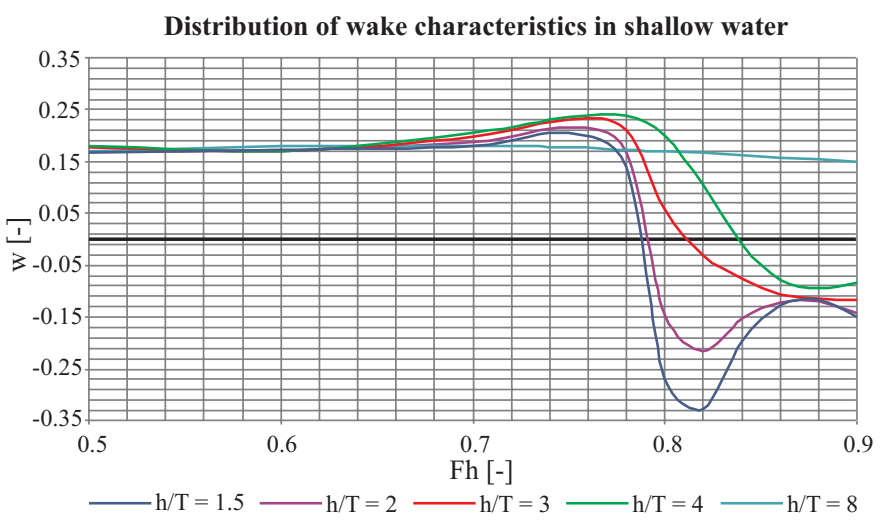

Fig. 3. Graphical representation

of the approximated hydrodynamic characteristics $\mathbf{w}(\overline{\mathbf{x}})$.

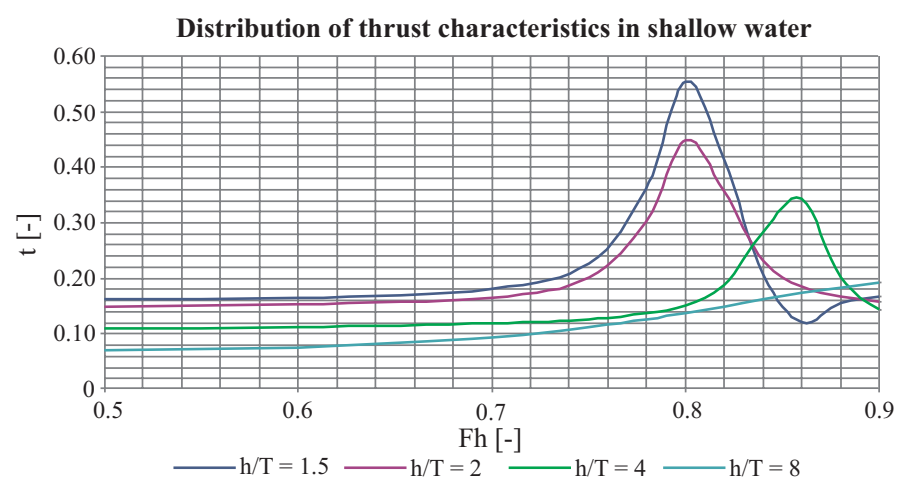

Fig. 4. Graphical representation

of the approximated hydrodynamic characteristics $\mathbf{t}(\overline{\mathbf{x}})$. 


\section{Example of application of the method}

The below presented numerical calculations were performed by means of the computer software [15]. Their results concern searching for optimum values of propulsion system parameters and speed of the ship designed within the frame of the EU Eureka E!3065 InCoWaTranS Project, and intended for tourist traffic along Polish inland waterways on the route Berlin - Królewiec.

The set of input parameters for the example task

Main particulars of two-segment ship :

- Ship's name ' $M / v$ Eureka InCoWaTranS'

- Total length of the train $(55 \mathrm{~m}+55 \mathrm{~m})$

$110.00[\mathrm{~m}]$

- Ship breadth

- Ship draught

- Ship mass displacement

$9.00[\mathrm{~m}]$

$1.00[\mathrm{~m}]$

$840.00[\mathrm{t}]$

$1.15[-]$

\section{Route parameters :}

- Length of deep-water part of the route

- Depth of deep-water part of the route

$250 \quad[\mathrm{~km}]$

$5.0 \quad[\mathrm{~m}]$

- Length of shallow-water part of the route $315 \quad[\mathrm{~km}]$

- Depth of shallow-water part of the route $2.0 \quad$ [m]

- Length of canals on the route $280 \quad[\mathrm{~km}]$

- Canal water depth
The constraints imposed upon permissible values of ship speed and trip duration time :

- Maximum ship speed in deep water

$15.0 \quad[\mathrm{~km} / \mathrm{h}]$

Maximum ship speed in shallow water

- Maximum ship speed in canals

$10.0 \quad[\mathrm{~km} / \mathrm{h}]$

- Voyage duration time

$7.0[\mathrm{~km} / \mathrm{h}]$

144 [h]

- Duration time of locking operations and port stays 24 [h].

\section{Engine parameters :}

- Specific fuel oil consumption 220 [g/kWh].

Financial parameter :

- Unit fuel oil cost $325[€ / t]$.

\section{Results of optimization calculations}

The results obtained from the first and last iteration of optimization calculations with the use of the above given task input data, are included in Tab.1, where the first row are results of the first iteration (fuel cost $=1462 €$ ), and the second row are the results of the last iteration (fuel cost $=877 €$ ), and the comprehensive full report from the calculations is included in [15].

The convergence process of selected results of optimization calculations in successive iteration steps is presented in Fig.5.

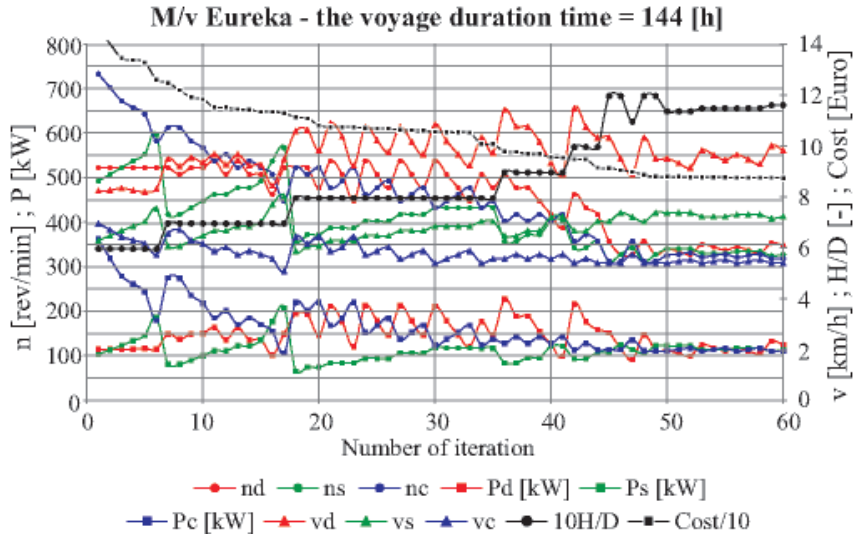

Fig. 5. Graphical representation of convergence process of selected results of optimization calculations

Tab. 1. Numerical results from the first and last iteration of optimization calculations

\begin{tabular}{|c|c|c|c|c|c|c|c|c|c|c|c|c|c|}
\hline Type & H/D & nd & ns & nc & vd & Eta0d & EtaPd & Rd & TNd & Pd & vs & Eta0s & EtaPs \\
\hline$[-]$ & {$[-]$} & {$[1 / \mathrm{min}]$} & {$[1 / \mathrm{min}]$} & {$[1 / \mathrm{min}]$} & {$[\mathrm{km} / \mathrm{h}]$} & {$[-]$} & {$[-]$} & {$[\mathrm{kN}]$} & {$[\mathrm{kN}]$} & {$[\mathrm{kW}]$} & {$[\mathrm{km} / \mathrm{h}]$} & {$[-]$} & {$[-]$} \\
\hline 4 & 0.60 & 525 & 495 & 735 & 8.28 & 0.376 & 0.273 & 13.8 & 14.9 & 118 & 6.32 & 0.251 & 0.238 \\
\hline 3 & 1.164 & 350 & 330 & 321 & 9.87 & 0.569 & 0.413 & 20.3 & 20.4 & 128 & 7.27 & 0.495 & 0.334 \\
\hline \hline Rs & TNs & Ps & $\mathbf{v c}$ & $\mathbf{E t a 0 c}$ & $\mathbf{E t a P c}$ & $\mathbf{R c}$ & $\mathbf{T N c}$ & $\mathbf{P c}$ & $\mathbf{C a v i t}$ & $\mathbf{J d}$ & $\mathbf{J s}$ & $\mathbf{J c}$ & Cost \\
\hline$[\mathrm{kN}]$ & {$[\mathrm{kN}]$} & {$[\mathrm{kW}]$} & {$[\mathrm{km} / \mathrm{h}]$} & {$[-]$} & {$[-]$} & {$[\mathrm{kN}]$} & {$[\mathrm{kN}]$} & {$[\mathrm{kW}]$} & {$[-]$} & {$[-]$} & {$[-]$} & {$[-]$} & {$[€]$} \\
\hline 14.7 & 15.1 & 106 & 7.00 & 0.209 & 0.198 & 38.4 & 39.3 & 365 & 1.01 & 0.30 & 0.24 & 0.18 & 1462 \\
\hline 20.3 & 20.3 & 116 & 5.45 & 0.413 & 0.274 & 21.4 & 21.5 & 113 & 0.53 & 0.54 & 0.42 & 0.33 & 877 \\
\hline
\end{tabular}

Description of selected items of Tab. 1. The following notation was applied : indices :

d - parameters concerning deep water

s - parameters concerning shallow water

c - parameters concerning canals.

Type: $1=$ Ka $3-65 ; 2=\mathrm{Ka} \mathrm{4-55;3=Ka} \mathrm{4-70;} \mathrm{4=Ka} \mathrm{5-75;}$

n - rotational speed of propeller

v - ship speed

Eta0 - open -water propeller efficiency
EtaP - behind-the-hull propeller efficiency

$\mathbf{R}$ - hull resistance in a given water area

TN - propelling force developed by propeller

P - demanded output power of the engine in a given water area

Cavit - index of Keller's cavitation criterion (Cavit $<\mathbf{1}$ - no cavitation)

J - propeller advance ratio

Cost - total cost of fuel oil consumed to cover voyage distance within a given time period. 


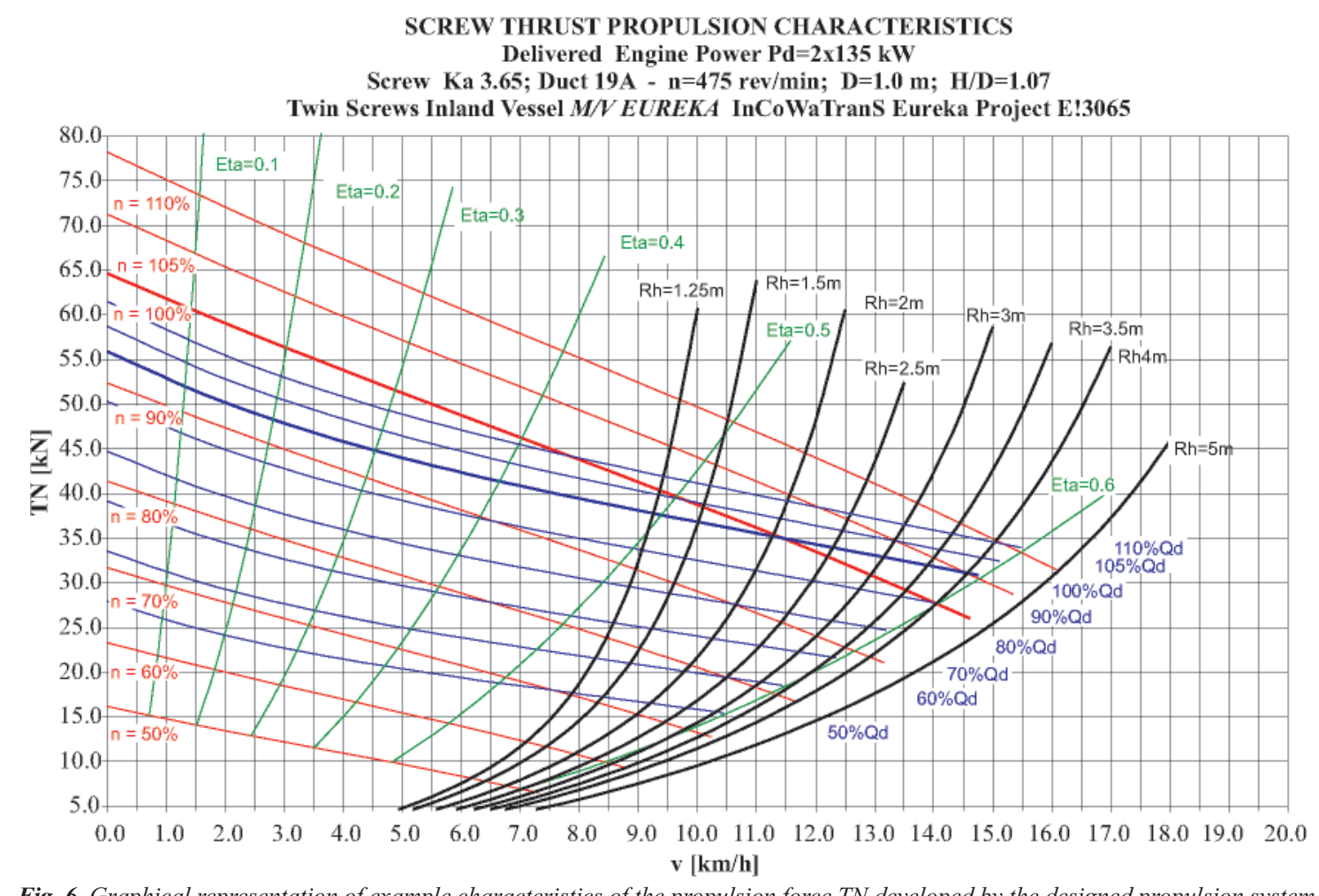

Fig. 6. Graphical representation of example characteristics of the propulsion force TN developed by the designed propulsion system.

The obtained results of optimization calculations can be used to select values of propeller parameters and an engine of appropriate output power and rotational speed, that makes it possible to elaborate characteristics of the engine and propeller and to analyze this way their interaction in changeable service conditions; so obtained characteristics are shown in Fig.6 in the form of the computer-processed diagram [15].

\section{SUMMARY}

O The computer implementation of the calculation algorithm realizing the presented mathematical model, makes it possible to effectively solve the design problem consisting in selection of optimum (here in the sense of minimizing fuel consumption cost) parameters of ship propulsion system fitted with fixed propeller, in the case of ship operating at changeable hull resistance characteristics, on a voyage route in waterways of changeable depth and width.

The presented results concern the example in which the designed ship has to cover its assumed voyage distance within $144 \mathrm{~h}$ including the duration time of port stays and locking operations equal to $24 \mathrm{~h}$. By changing the effective voyage duration time, different optimum values of design parameters of the propulsion system can be respectively obtained.

O The presented design method is fully algorithmic and it does not require to appeal to designer's experience and intuition, hence it can serve to objectively, effectively and immediately find complex, difficult for intuitive assessment, solutions for propulsion system design problems.

O The method may also serve as a useful tool in aiding the design process in the phase preceding model tests as well as in determining the scope of model test program.

\section{NOMENCLATURE}

b - route section width

B - ship breadth

D - propeller diameter $[\mathrm{m}]$

Fh - Froude number related to depth of water area

gj - specific fuel oil consumption [g/kWh]

h - route section depth

$\mathrm{H}$ - propeller pitch [m]

$\mathrm{J}$ - propeller advance ratio [-]

$\mathrm{k}=0.1$ - constant in Keller's cavitation criterion

$\mathrm{kj}$ - unit fuel oil cost [€/t $]$

$\mathrm{K}$ - fuel cost

$\mathrm{K}_{\mathrm{T}^{-}}$propeller thrust coefficient characteristics [-]

$\mathrm{K}_{\mathrm{Q}}$ - propeller torque coefficient characteristics [-]

$\mathrm{m}$ - number of route sections

$\mathrm{n}$ - number of propeller rotations

$\bar{p}$ - vector of water area parameters

$\mathrm{p}_{\mathrm{d}}$ - saturated water vapour pressure

$\mathrm{p}_{\mathrm{i}}$ - parameter of a water area and ship

$\mathrm{p}_{\mathrm{o}}$ - water pressure at propeller axis

$\mathrm{P}$ - propulsion power $[\mathrm{kW}]$

$\mathrm{r}$ - route section length

$\mathrm{R}$ - hull resistance $[\mathrm{kN}]$

$\mathrm{R}_{\mathrm{i}}$ - hull resistance in $\mathrm{i}$-th water area $[\mathrm{kN}]$

$\overline{\mathrm{s}}$ - vector of propeller parameters

$\mathrm{t}$ - thrust deduction characteristics [-]

$\mathrm{T}$ - propeller thrust, ship's draught

$v$ - ship speed $[\mathrm{km} / \mathrm{h}]$

$v_{i}$ - ship speed developed in i-th water area $[\mathrm{km} / \mathrm{h}]$

vs - route section current speed

$\mathrm{Q}$ - engine torque

$\mathrm{w}$ - wake fraction characteristics [-]

$\bar{x}-$ in general, vector of variable design arguments

z - number of propeller blades [-]

$\eta$ - propulsion system efficiency [-]

$\eta_{p}$ - efficiency of open - water propeller [-]

$\eta_{t}$ - power transmission efficiency, from engine to propeller [-].

$\tau$ - voyage duration time $[\mathrm{h}]$ 
$\tau_{0}$ - duration time of port stays and locking operations [h]

$\tau_{\mathrm{i}}$ - time to cover distance of $\mathrm{i}$-th route section [h]

$\tau_{\mathrm{z}}$ - assumed time period to cover voyage distance

$\xi_{\mathrm{k}}$ - hull "efficiency" characteristics [-]

$\xi_{\mathrm{r}}$ - rotational efficiency [-]

$\xi_{\mathrm{i}}$ - additional resistance factor in i-th water area [-].

\section{BIBLIOGRAPHY}

1. Bojko J.: Development of US Navy (in Polish). Bandera. February 2004

2. Kobyliński L.: Ship propellers (in Polish). Transport Publishing House (Wydawnictwa Komunikacyjne). Warszawa 1955

3. Carlton J.S.: Marine Propellers and Propulsion. Butterworth Heineman

4. Basin A.M., Miniowicz I.J.: Teoria i rasczet grebnych wintow (in Russian). Leningrad 1963

5. Szantyr J.: Designing the controllable pitch propellers by means of electronic digital machine (in Polish). $3^{\text {rd }}$ Symposium on Ship Hydrodynamics - Hydrodynamic problems of ship propulsion. IMP PAN. Gdańsk 1975

6. Kulczyk J., Winter J.: Inland waterways transport (in Polish). Publishing House of Wrocław University of Technology (Oficyna Wydawnicza Politechniki Wrocławskiej). Wrocław 2003

7. Więckiewicz W.: Changes of ship resistance in service versus performance of ship propeller (in Polish). $3^{\text {rd }}$ Symposium on Ship Hydrodynamics - Hydrodynamic problems of ship propulsion. IMP PAN. Gdańsk 1975

8. Basin A.M., Wjelednickij I.O., Ljakowickij A.G.:

Gidrodinamika sudow na mietkowodie (in Russian). Izdatielstwo Sudostroienie. Leningrad 1976

9. Żylicz A.: Inland waterways ships (in Polish). Maritime Publishing House (Wydawnictwo Morskie). Gdańsk 1979.

10.Dudziak J.: Theory of ships (in Polish). Maritime Publishing House (Wydawnictwo Morskie). Gdańsk 1988
11. Kuiper G.: The Wageningen propeller series. MARIN Publication. Netherlands 1992

12.Rogalski A., Grygorowicz M.: Model test results of a tourist hotel passenger ship in deep and shallow water (in Polish). Research report No. 126/E/2004, Faculty of Ocean Engineering and Ship Technology, Gdańsk University of Technology, 2004

13.Michalski J.P.: Mathematical model for selecting optimum parameters of propulsion system of inland waterways ships approximation of experimental characteristics of hull resistance (in Polish). Research report No. 182/E/2005, Faculty of Ocean Engineering and Ship Technology, Gdańsk University of Technology, 2005

14.Michalski J.P.: Calculation algorithms and DUCT PROPELLER.VBA computer software for determining and visualizing hydrodynamic characteristics of KA screw propellers ducted in the Kort nozzle No 19A, intended for designing propulsion systems of inland waterways ships (in Polish). Research report No. 204/E/2005, Faculty of Ocean Engineering and Ship Technology, Gdańsk University of Technology, 2005

15.Michalski J.P.: A method for designing optimum parameters of compromise screw propellers and service speed of inland waterways ships in restricted waters (in Polish). Research report No. 225/E/2005, Faculty of Ocean Engineering and Ship Technology, Gdańsk University of Technology, 2005

\section{CONTACT WITH THE AUTHOR}

Assoc. Prof. Jan P. Michalski

Faculty of Ocean Engineering and Ship Technology

Gdansk University of Technology

Narutowicza 11/12

80-952 Gdansk, POLAND

e-mail : janmi@pg.gda.pl

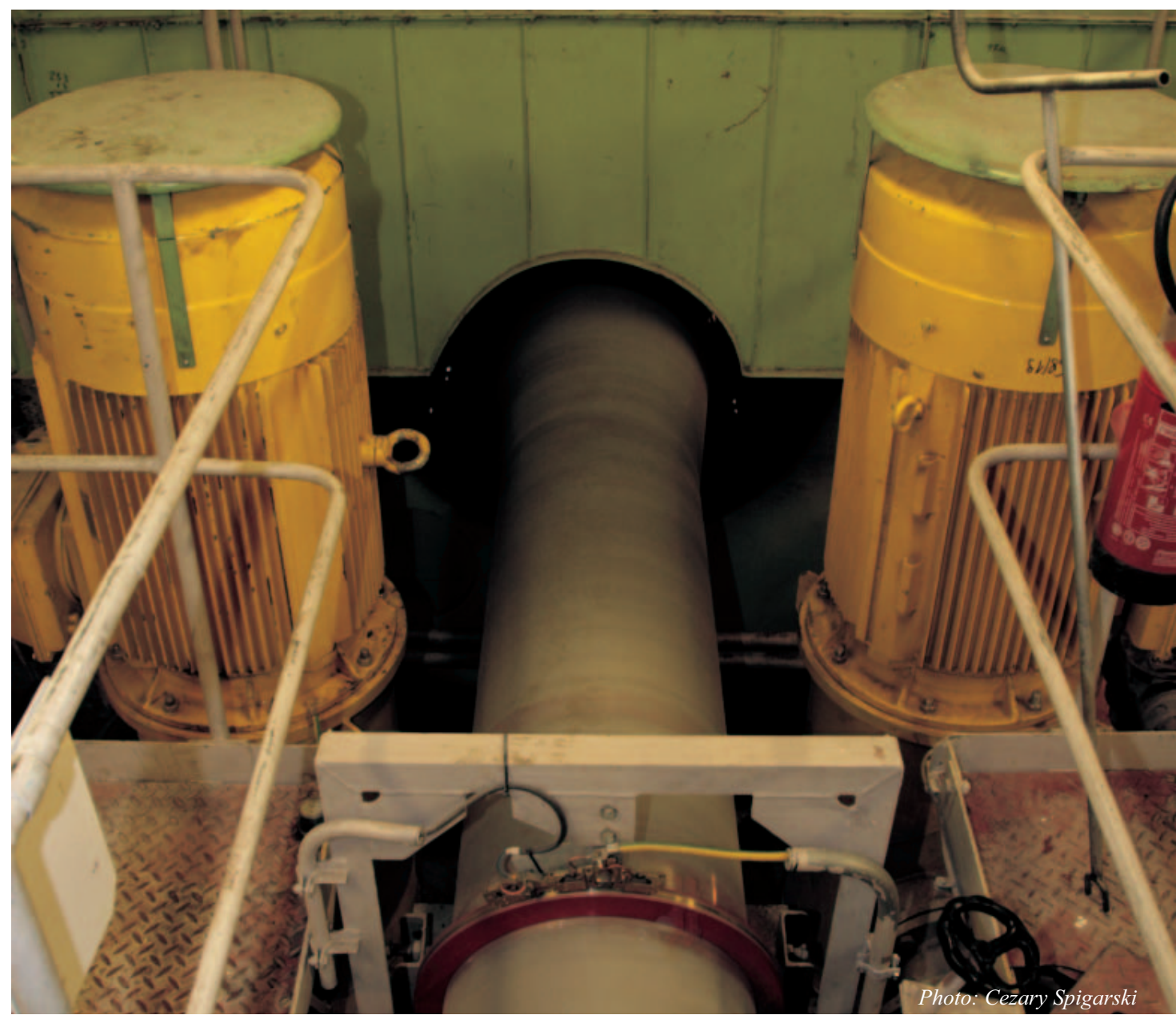

